ISSN: 1641-4713; e-ISSN: 2081-1160

DOI: https://doi.org/10.36551/2081-1160.2021.28.225-244

\title{
La democracia en disputa: Mujeres y feministas ante el proceso de transición hacia la democracia en Chile ${ }^{1}$
}

Democracy in dispute: Women and feminists in the process of transition to democracy in Chile

Claudia Maldonado Salazar

Taller de Historia Reciente, Chile ORCID iD: https://orcid.org/0000-0002-8398-0440

E-mail: camaldonados499@gmail.com

Recepción: 29.04.2021

Aprobación: 15.09.2021

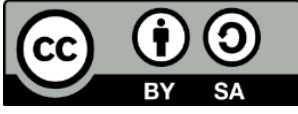

Resumen: En este artículo se realiza una aproximación al rol de las mujeres y feministas en el proceso de transición a la democracia que se comienza a perfilar durante la década de los ochenta en Chile, a partir del análisis de las demandas y propuestas que estas elaboran. Así, en primer lugar, se caracteriza el discurso y las acciones que la dictadura cívico-militar dirigió hacia las mujeres (1973-1989) para luego dar cuenta cómo las mujeres re-accionaron ante las mismas. Posteriormente, se analizan las principales demandas que mujeres y feministas construyeron a lo largo de los ochenta, con un especial énfasis en la experiencia de la Concertación de Mujeres por la Democracia. Tras este ejercicio se concluye que el gran aporte del movimiento social de mujeres al proceso de cambio de régimen político fue el posicionamiento de una nueva definición de democracia, que evidenció las fisuras del proceso transicional chileno.

Palabras clave: movimiento social de mujeres, transición democrática, democracia, feministas, Chile.

\footnotetext{
${ }^{1}$ Este trabajo se vincula con temáticas abordadas en mi tesis para optar al grado de Magíster en Historia, titulada "Mujeres en transición. Elaboración de saberes y debate de ideas de mujeres y feministas intelectuales en el Chile postdictatorial", Universidad de Concepción (Chile), 2020.
} 


\begin{abstract}
In this article, an approach is made to the role of women and feminists in the process of transition to democracy that began to take shape during the eighties in Chile, based on the analysis of the demands and proposals that they elaborated. Thus, in first place, we characterize the discourse and actions that the civic-military dictatorship directed towards women (1973-1989) and then we describe how women reacted to them. Subsequently, we analyses the main demands that women and feminists built throughout the eighties, with a special emphasis on the experience of the Concertación de Mujeres por la Democracia. After this exercise, it is concluded that the great contribution of the social movement of women to the process of change of political regime was the positioning of a new definition of democracy, which evidenced the fissures of the Chilean transitional process.
\end{abstract}

Keywords: women's social movement, democratic transition, democracy, feminists, Chile.

\title{
1. INTRODUCCIÓN
}

El proceso chileno de transición hacia la democracia por mucho tiempo fue analizado como un caso exitoso de cambio de régimen político, caracterizado por la calma social y estabilidad institucional con la que se llevó a cabo. Esta sensación de éxito que inundó a la política chilena a principios de los noventa fue, sin embargo, criticada tempranamente por intelectuales que evidenciaron los vicios del proceso, cuestionando hasta qué punto el régimen dictatorial había quedado efectivamente en el pasado.

Mientras para algunos de estos intelectuales la transición chilena fue en realidad una transición incompleta con escasas posibilidades de consolidar un régimen democrático (Garretón, 1989, 1990), para otros fue una transición pactada entre la dictadura militar y la oposición que impediría un desarrollo autónomo del proceso de democratización (Godoy, 1999). Así, la única excepcionalidad del caso chileno se encontraba en el éxito que la cúpula militar tuvo en llevar adelante un proyecto neoliberal que estableció una democracia protegida (Moulian, 1998).

Transición pactada o incompleta, lo cierto es que todas estas interpretaciones refieren a un proceso que se resolvió por arriba y que no fue capaz de reconocer los aportes que diversos grupos y sujetos sociales cultivaron desde la resistencia y oposición a la dictadura cívico-militar chilena. Las mujeres y, más específicamente, el movimiento social de mujeres, son un claro ejemplo de esta situación. De ahí que en este artículo me interesa describir y analizar el rol de las mujeres y feministas chilenas en la década de los ochenta en Chile, por ser un periodo en que se comienza a perfilar el proceso de transición hacia la democracia, y en donde éstas inician un trabajo de elaboración de propuestas y demandas hacia el nuevo régimen. Para concretarlo, en primer lugar, se caracteriza el discurso y las acciones que el régimen militar dirigió hacia las mujeres, para luego 
describir cómo éstas actuaron desde su organización en el movimiento social de mujeres. En segundo lugar, se analizan las demandas y las propuestas que se construyen en el seno de dicho movimiento, con especial énfasis en aquellas construidas por la Concertación de Mujeres por la Democracia a fines de los ochenta, instancia organizativa independiente pero dialogante con los partidos políticos que en 1990 asumen el primer gobierno civil tras la dictadura.

\section{LO FEMENINO Y LAS MUJERES BAJO EL RÉGIMEN DICTATORIAL, -1973-1989-}

La Junta Militar, que toma el poder a través del golpe de Estado del 11 de septiembre de 1973, dirigió gran parte de su discurso y acciones a ciertos grupos de la sociedad caracterizados como estratégicamente claves para sus objetivos. Las mujeres, especialmente de clase media y alta, se mostraron como una fuerza importante en la oposición al gobierno de Salvador Allende (Power, 2008), de modo que la Junta Militar encontró en ellas una potencial alianza. A través de la experiencia femenina, en tanto que víctimas del marxismo, encarnaron la terrible experiencia que la Unidad Popular había representado, toda vez que en la visión de la Junta:

cada hogar fue un bastión de rebeldía [...] la altivez anónima de la dueña de casa, que resistió a la presión indigna del racionamiento [...]. La mujer quería la caída del gobierno marxista, que simbolizaba la esclavitud para sus hijos (Gobierno de Chile, 1974, p. 193).

El supuesto desorden social sobre el cual los militares justificaron el golpe de Estado no solo se expresaba en términos económicos y político-institucionales, sino que también en las prácticas sociales que habían asumido, principalmente, la juventud y las mujeres. La falta de moralidad, la permisividad sexual, la pérdida del respeto a la autoridad en la familia y la masculinización de las mujeres de la izquierda, entre otras cosas, eran expresión de un orden perdido que era necesario reencauzar a partir de la reimposición de los valores femeninos tradicionales, tales como la maternidad, la devoción a la familia, la virginidad y el respeto al matrimonio.

Esta instrumentalización de lo femenino no desconoció totalmente las transformaciones ocurridas a lo largo del siglo en torno a las posibilidades que las mujeres tuvieron para desenvolverse como tal en la sociedad, en específico, en lo relativo a su formación educacional y profesional. Rescatando estos elementos, la dictadura las llamó a colaborar en la erradicación de la pobreza desde 
sus profesiones, misión que de forma relativamente autónoma las mujeres habían comenzado a asumir desde los comienzos del siglo XX. Así, la participación de las mujeres que el régimen incentivó se centró específicamente en las tareas sociales que estas podían desarrollar, principalmente, en los Centros de Madres y en la Secretaría Nacional de la Mujer, que se posicionaron como espacios que le permitieron a los militares ir construyendo la base social necesaria para sustentar las políticas y acciones que impulsaron en los años posteriores. "Consideramos por eso que una autentica participación de la mujer en la vida nacional, debe ser ejercida con respeto a sus características, y el Estado se propone orientar su acción en este sentido". (Junta Nacional de Gobierno, 1974, p. 195).

La cita anterior describe muy bien el lugar de enunciación de las políticas estatales creadas durante la dictadura en relación a las mujeres. En lo relativo a la condición civil de la mujer, en 1975 se formó una comisión por encargo del ministro de Justicia que propuso en 1979 otorgar la capacidad civil a la mujer casada y erradicar la potestad marital por la cual el marido portaba la representación jurídica de la mujer, lo cual, sin embargo, no logró concretarse. Así, la supuesta igualdad de los sexos proclamada en textos jurídicos no era tal en la realidad, toda vez que mientras "la mujer debe obediencia al marido", este último debe "protección a la mujer"; en ese sentido, la sociedad conyugal dejaba a la mujer en calidad de incapaz relativo, todo en virtud de la "patria potestad" (Valdés, 1987, p. 7). Esta situación no cambió hasta los últimos momentos del régimen pinochetista, cuando en 1985 resolvió implementar una reforma parcial que concedía a la mujer casada la plena capacidad y, en teoría, erradicaba la potestad marital pero sin alterar el régimen patrimonial, manteniéndose el hombre como administrador (Htun, 2010).

En cuanto a derechos sexuales y reproductivos, la dictadura representó un retroceso significativo al rechazar y suspender todas las políticas levantadas por gobiernos anteriores en esa materia. Se pusieron restricciones a la esterilización, haciéndola depender de la autorización del marido o conviviente y de una comisión médica, exigiendo, además, requisitos de edad y número de hijos. En 1979 se optó por una política de crecimiento demográfico que suspendió las políticas de educación sexual en consultorios y medios de comunicación, prohibiendo la esterilización como método de prevención de los embarazos y desincentivando el uso de anticonceptivos orales y dispositivos intrauterinos, autorizando su retiro del mercado sin consulta previa a las usuarias. Todas estas medidas fueron aumentando el poder que el Estado ostentaba sobre los cuerpos de mujeres, limitando las posibilidades de estas últimas de desarrollarse libremente en el plano sexual y planificar sin restricciones su vida. 
Los supuestos beneficios del nuevo modelo económico implantado tardaron en llegar por lo que, sobre todo en los primero años de la dictadura, la Junta Militar constantemente hizo una llamado a la paciencia y al apoyo por parte de todos los sectores, específicamente de las mujeres, cuya participación era vista como "necesaria en la movilización de recursos, indispensable para arrancar al país del retraso y de la pobreza en que nos han sumido la demagogia de los irresponsables y el sectarismo de los marxistas" (Junta Nacional de Gobierno, 1974, p. 24). Así, pese a que se reconoce la contribución femenina a la producción nacional, esta se comprende como un "mal necesario", consecuencia de "la vida moderna [que] ha abierto en todo el mundo vastas perspectivas de actividad y de trabajo, en las cuales la mujer colabora con plena competencia y eficacia" (Junta Nacional de Gobierno, 1974, p. 25).

La obtención de trabajos remunerados por parte de las mujeres abrió las posibilidades de una independencia hasta entonces desconocida, liberándolas del control de sus esposos y permitiéndoles tener una vida más libre en términos sociales y sexuales. Ahora bien, esta transgresión de los valores femeninos conservadores y tradicionales que la Junta Militar insistía en instalar discursivamente, encontró su mayor contradicción en el desarrollo del mercado del sexo. Para las mujeres esto significó una fuente de trabajo importante que, por el horario en que se desarrollaban estas actividades, les permitió contar con más de un ingreso. Sin embargo, la falta de requisitos como formación educacional y/o profesional, más la necesidad de trabajos remunerados, condujo a que muchas mujeres jóvenes - desde los 16 años- ingresaran a este tipo de actividades, abandonando sus estudios para así ayudar a sus familias y desarrollándose tempranamente en la prostitución encubierta (Valdivia, 2010).

Todo lo visto evidencia que las mujeres se transformaron en las principales destinatarias de los mensajes de la dictadura, ya fuera como consumidoras en el plano económico, o como reproductoras y socializadoras de las nuevas generaciones en el plano político. Desde esas dos dimensiones, el régimen instrumentalizó constantemente a las mujeres, y, en tanto buenas madres y cuidadoras, se les mantuvo lejos de la política, situándolas como potencial freno a la movilización y la protesta (Valdés, 1987). Pese a ello, el paso del tiempo evidenciaría la creciente contradicción entre el modelo económico instalado por el régimen militar y el discurso conservador que este portaba. Como señala la historiadora chilena Verónica Valdivia (2010) en su estudio sobre el mercado del sexo durante la dictadura: 
la posibilidad ilimitada de desarrollar este mercado, como se observó entre 1979 y 1983, demuestra una vez más que la meta más importante para el régimen militar era la transformación económica del país- con su correlato sociocultural-, propósito al que se subordinaban todos los otros intereses y discursos, incluyendo sus afanes de restauración conservadora (p. 108).

Estas contradicciones y el constante hostigamiento y la represión que la dictadura ejerció sobre las mujeres condujeron al desarrollo de un proceso inverso al perseguido. Esto es, de negación de la opresión, en que las mujeres crearon espacios para su organización autónoma, que en la década de los ochenta les posicionó como gran fuerza opositora al régimen autoritario.

\section{DE LA RESISTENCIA A LA OPOSICIÓN: EL MOVIMIENTO SOCIAL DE MUJERES}

Pese a la diversidad de formas en que las mujeres se organizaron durante la dictadura, y más específicamente durante los ochenta, existe cierto consenso en los estudios sobre el periodo en identificar momentos o etapas en el desarrollo del movimiento de mujeres. Siguiendo la propuesta de Sandra Palestro (1991), investigadora feminista e integrante del movimiento social de mujeres durante la dictadura, estos serían cuatro momentos identificados a partir de las políticas y estrategias implementadas por el régimen militar y la forma en que las mujeres re-accionaron ante las mismas.

El primero de esos momentos se caracteriza por la organización en defensa de la vida. Irónicamente, en consonancia con el discurso de la dictadura, la familia fue uno de los espacios de enunciación que las mujeres emplearon para denunciar la represión de la que eran víctimas sus cercanos. De esta manera se gestó una movilización en defensa de la integridad de los hogares amenazados por la violencia del Estado (Valenzuela, 1993). Así surgieron las primeras organizaciones en defensa de los derechos humanos tales como la Agrupación de Familiares de Detenidos Desaparecidos y la Agrupación de Familiares de Prisioneros Políticos, las cuales estuvieron integradas principalmente por mujeres y cuyo objetivo central fue la denuncia y la obtención de información sobre las y los detenidos. Posteriormente aparecieron las Agrupaciones de Familiares de Ejecutados Políticos, de Relegados y ex Relegados y el Comité Pro Retorno de Exiliados. Muchas de las mujeres que formaron parte de estos espacios no contaban ni con militancia política ni con mayor experiencia en ese ámbito. Por tanto, su participación en estas agrupaciones las llevó a un proceso de formación política que 
con los años desembocó en un gran compromiso con la defensa de los derechos humanos (Palestro, 1991).

La profunda crisis económica que afectaba el país, más las consecuencias de las políticas económicas impulsadas por el régimen, generaron una situación de desempleo que obligó a las mujeres a levantar alternativas para enfrentar esta compleja situación. Así surgen diversas organizaciones de subsistencia, en un principio al alero de la Iglesia Católica y con el paso del tiempo adquiriendo altos niveles de autonomía. Comedores populares y ollas comunes fueron los espacios que diversas mujeres compartieron, dando lugar a conversaciones en que se fueron colectivizando otro tipo de problemas que les había tocado vivir y enfrentar de manera solitaria, pero que ahora encontraba eco en la experiencia de otras mujeres. Este fenómeno conduce al segundo momento-1977-1981-, en que las mujeres comienzan a preguntarse sobre su problemática específica.

En este periodo, y en paralelo a las organizaciones mencionadas más arriba, se comienzan a levantar espacios que buscaban generar talleres de autoconciencia en que se discutía la situación de vida de mujeres. La proliferación de este tipo de talleres y colectivos condujo a la necesidad de levantar espacios amplios, de carácter nacional, en que las mujeres se volcaron a discutir sobre sus preocupaciones, surgiendo así los Encuentros Nacionales de Mujeres ${ }^{2}$. Estos espacios de encuentro y debate más amplio, pusieron en evidencia la diversidad de mujeres que se sentían atraídas por la fuerza de este movimiento naciente, lo que trajo consigo el enfrentamiento de posiciones distintas y en abierta tensión en torno a las prioridades del movimiento y las relaciones que se debían o no tener con los partidos políticos.

Los primeros años de la década de los ochenta no fueron fáciles para la administración militar, pese al resultado positivo que se obtuvo en el plebiscito de $1980^{3}$. A la crisis económica mundial que afectó especialmente al joven modelo económico instalado, se suman las transformaciones en el plano internacional en que diversos países iniciaron procesos de democratización o de transición a la democracia que hicieron tambalear la estrategia política del régimen. Las transformaciones que sufrió esta última, más la imposibilidad de ocultar las violaciones a los derechos humanos, condujeron al rearme de la oposición y a las negociaciones entre ésta y los militares para avanzar hacia un régimen democrá-

\footnotetext{
${ }^{2}$ El primero de ellos se celebró en 1978.

${ }^{3}$ El 8 de agosto de 1980 se convoca a un plebiscito de ratificación de la nueva Constitución. Este último, desarrollado en estado de emergencia y bajo serias limitaciones políticas, que impidieron la correcta difusión y análisis del texto, terminó con un resultado favorable para la opción Sí (67,04\%).
} 
tico. Este clima inestable favoreció el desarrollo de las primeras Jornadas de Protesta Nacional que, pese a que no lograron terminar con la dictadura, develaron la fuerza de la resistencia.

Las mujeres se sumaron con fuerza a esta nueva fase de lucha anti-dictatorial, contribuyendo al paso de la resistencia hacia la oposición desde una posición de género y, en algunos casos, feminista. Lo anterior, entre otras cosas, es lo que permite identificar un tercer momento del desarrollo del movimiento de mujeres-1982-1986-, caracterizado por la movilización contra la dictadura desde sus demandas específicas. La consigna "Democracia en el País y en la Casa" desplegada por el Movimiento Feminista en las escaleras de la Biblioteca Nacional en el marco de la Primera Protesta Nacional en 1983, es un claro ejemplo de este nuevo momento. La demanda feminista se sumaba a la lucha contra la dictadura, pero ampliando esa lucha contra el autoritarismo en todos los espacios que permitían la reproducción de la discriminación hacia las mujeres, tales como la familia, los partidos políticos y el Estado (Valenzuela, 1993). Ello devela transformaciones significativas en las bases ideológicas del movimiento, que tuvieron mucha importancia para los debates sobre democracia y los medios para alcanzarla ${ }^{4}$.

Los intentos de coordinación más amplia entre organizaciones de mujeres proliferaron durante este periodo. Un ejemplo de aquello fue Mujeres por la Vida, creada en 1983 e integrada en un inicio por 16 mujeres, una de las organizaciones con mayor capacidad de convocatoria y concertación en la movilización social de las mujeres. Mujeres por la Vida convocó a la mayor concentración de la oposición realizada durante la dictadura hasta ese momento, en lo reconocido como el Caupolicanazo, en donde 10.000 mujeres se reunieron en un gran acto políticocultural, cuya invitación fue:

Hoy y no mañana venimos juntas a expresar la decisión de actuar y unir nuestra determinación. Hoy y no mañana para poner fin a los signos de la muerte: tortura, hambre, desempleo, detenidos desaparecidos, exilio, detenciones arbitrarias represión y abusos de poder (Citado en Tessada, 2013, p. 114).

En Mujeres por la Vida participaban mujeres con y sin militancia política, pero lo hacían desde su individualidad y no como representantes de organizaciones o partidos, por lo que al interior de la misma podían surgir visiones diversas y a veces abiertamente opuestas, representando un esfuerzo diferente y exitoso de unir a las mujeres de oposición (Baldez, 2002).

\footnotetext{
${ }^{4}$ Entre las organizaciones que surgen en este periodo, se cuentan MUDECHI (1981), MOMUPO (1982), la Unión Chilena de Mujeres (1983), y el MEMCH' 83.
} 
En 1983, se llevó a cabo el Segundo Encuentro Feminista Latinoamericano y del Caribe en Lima, el que tuvo un impacto considerable tanto en el continente como en Chile. Como tantas veces se escuchó decir, "todo fue distinto después de Lima" (Kirkwood, 1984, p. 1). Y es que al sentido descubridor que marcó al Primer Encuentro, le siguió un sentido de necesidad por tener una estrategia y una teoría política feminista ${ }^{5}$ que se hizo patente en este Segundo Encuentro. A partir de este acontecimiento, nuevas organizaciones feministas se comenzaron a cuestionar el rol histórico de las mujeres y del feminismo (Gálvez, 2018), haciéndose cada vez más evidentes las diferencias estratégicas de los feminismos allí presentes, y que luego Kirkwood conceptualizó como las diferencias entre feministas y políticas. La discusión entre ambas posiciones se mantuvo durante toda la década de los ochenta en torno a dos ejes. Uno teórico, en que las diferencias estaban dadas por la manera de entender la democracia, en que por un lado, para las políticas "no hay feminismo sin democracia", de modo que lo primero era la lucha opositora al gobierno autoritario y luego las cuestiones de la mujer; mientras que por el otro lado la fórmula estaba dada por "no hay democracia sin feminismo", postura defendida por las feministas quienes descartaban las posibilidades de establecer prioridades entre cada causa (Ríos et al., 2003). El otro eje del debate se dio en términos estratégicos, dado por el conflicto en torno a la doble militancia que en definitiva expresaba dos formas de hacer política que entraban en conflicto y a veces en contradicción: por una parte, la posibilidad de hacer política desde las mujeres y a partir de sus identidades y propuestas; $\mathrm{y}$, por otra parte, sumar a las mujeres a una propuesta política tradicional masculina.

Pese a lo anterior, el recrudecimiento de las medidas represivas de la dictadura desde 1986 y las posibilidades de derrotarla a través del plebiscito que se acercaba, parecen haber aplacado dichas diferencias, al menos por un tiempo. Así, en 1986 Mujeres por la Vida elaboró el "Pliego de las Mujeres" (Valdés, 1987), a partir de las demandas explicitadas por organizaciones femeninas en todos los textos existentes a la fecha lo que abre una nueva fase en el desarrollo del movimiento.

\section{LAS MUJERES Y LAS POSIBILIDADES DE DEMOCRATIZACIÓN}

Pese a los intentos de la oposición partidaria por generar alianzas y estrategias conjuntas para terminar con la dictadura cívico-militar, la lentitud y debilidad de dichos acuerdos, y el recrudecimiento del aparato coercitivo, fueron

\footnotetext{
${ }^{5}$ Es a partir de la experiencia del Segundo Encuentro que Julieta Kirkwood elabora la idea del nudo del conocimiento y el nudo del poder, como los dos centros de la controversia (Kirkwood, 1984).
} 
evidenciando para algunos que el camino trazado por la Constitución de 1980 sería el más viable para recorrer en miras de un cambio de régimen ${ }^{6}$.

El plebiscito de 1988, que para muchos y muchas marca el inicio del proceso de democratización, fue un hito caracterizado por disputas y negociaciones que, poco a poco, fueron configurando el clima de consensos y realismo político que daría lugar al fin de la dictadura. Si bien, parte de la oposición pudo festejar el triunfo del NO, aún quedaba por delante un año de gobierno militar, además de un proceso de reformas constitucionales y elecciones presidenciales y parlamentarias que hicieron de estos dos años un periodo clave para el devenir político de Chile.

Tras el triunfo del $\mathrm{NO}$ en el plebiscito ${ }^{7}$, se inicia el proceso de elaboración de los programas de gobierno que se enfrentaron en las elecciones presidenciales de diciembre de 1989. Si bien las mujeres no participaron de las negociaciones, toda vez que estas fueron conducidas exclusivamente por los partidos políticos, sí jugaron un rol muy activo en la elaboración de propuestas y demandas para la democracia que se acercaba.

Estas últimas ya se habían comenzado a construir en el movimiento desde los primeros años de la década del ochenta. Así, el proceso de elaboración de 1988 y 1989 tuvo ese trabajo como antecedente, lo que favoreció que esa acumulación de experiencias y aprendizajes se expresara en la propuesta de finales de la década. El primero en surgir corresponde al "Manifiesto Feminista" presentado en 1983, en el que se plantea una premisa clave para comprender la noción de democracia que se elaboraba desde la experiencia de las mujeres, relativa a que ningún proyecto de democratización es viable sin la participación efectiva de las mujeres. A partir de ello, se elaboran una serie de demandas articuladas en los siguientes ejes: política, trabajo-remunerado, doméstico, cesantía-, Seguridad Social y Estado, educación-formal e informal-, familia, legal, y violencia.

Luego, en 1986, organizaciones del movimiento social de mujeres presentan el "Pliego de las Mujeres" a la Asamblea de la Civilidad", en que nuevamente se plantea que: "No es posible concebir una sociedad realmente democrática sin la real democratización de la condición de la mujer". Algunos de los

\footnotetext{
${ }^{6}$ La Constitución de 1980 establecía un periodo de transición con sus respectivos artículos transitorios que daba el tiempo suficiente para la consolidación del modelo político-económico instaurado, así como también para la preparación del plebiscito de 1988, para el que los comandantes en Jefe del Ejército y el General Director de Carabineros propondrían un candidato presidencial para gobernar por ocho años más.

${ }^{7}$ El plebiscito se dio entre la opción SÍ, que implicaba la mantención de Augusto Pinochet en el gobierno, y la opción NO, que permitía el desarrollo de elecciones presidenciales y parlamentarias.

${ }^{8}$ Instancia organizativa de la oposición.
} 
elementos fueron recogidos por ese espacio en la "Demanda de Chile" (Valdés, 1987). Sin embargo, ninguno de ellos logró concretarse. Este documento, a diferencia del anterior, se encuentra dividido en dos tipos de demandas. Por una parte, aquellas definidas como inmediatas y dirigidas al régimen militar, entre las que se encuentran el respeto a la vida, los derechos humanos y la dignidad de las personas. Y, por otra parte, aquellas reivindicaciones que se entienden como posibles de alcanzar bajo un régimen democrático. Estas últimas contemplan la igualdad ante la ley, una mayor participación de las mujeres, la ratificación de la Convención de las Naciones Unidas para la Eliminación de todas las Formas de Discriminación contra la Mujer-CEDAW por sus siglas en inglés-, y otras aglutinadas bajos los ejes de trabajo, educación y familia.

Pese a la importancia que tuvo la elaboración del citado Pliego como instancia de sistematización de experiencias, sus mismas creadoras señalaban que aún faltaba avanzar hacia una propuesta más concreta ${ }^{10}$. Otras planteaban también que las demandas contenidas en el mismo eran vistas como lejanas para las mujeres pobladoras o rurales, haciéndose necesaria su difusión y localización en esos espacios.

Aunque estos documentos no se materializaron en la incorporación de las demandas en el programa o planteamientos de los partidos políticos, sí constituyeron ejercicios importantes de sistematización del trabajo y de las reflexiones que el movimiento social de mujeres había dado durante todos esos años. Permitieron no solo instalar en la sociedad el diagnóstico que las mujeres tenían sobre sí mismas sino también construir propuestas en miras de transformar la situación de desigualdad en la que se encontraban. En ese sentido, estos documentos representan un tránsito de la reflexión personal y colectiva que se daba al interior del movimiento hacia un momento de difusión y necesaria instalación de aquellos elementos en la agenda política que se comenzó a abrir durante la década de los ochenta, lo que alcanza un nuevo nivel cuando se acerca el plebiscito.

En medio del proceso de campaña por el NO, las mujeres decidieron ir más allá de la simple consigna de No más dictadura y sumar contenido al debate por la democracia desde su condición genérica específica. Para aquello elaboraron el documento "A las mujeres chilenas. Demandas de las mujeres a la democracia" (1987). Las primeras demandas que se expresaban para su incorporación

\footnotetext{
${ }^{9}$ Documento creado por la Asamblea de la Civilidad y presentado a los militares en que, entre otras cosas, llamaba a la apertura de los registros electorales y el desarrollo de elecciones libres (1986). ${ }^{10}$ Así señalaba Eliana Largo, coordinadora del Movimiento Feminista, al decir que: "Las reivindicaciones están solo enunciadas pero debemos contextualizarlas para que así se entienda porqué las mujeres estamos haciendo las demandas que el pliego contiene" ("Cuatro miradas al pliego de la mujer", 1986).
} 
a la democracia eran: la ratificación de la CEDAW; la creación de un organismo con rango ministerial que elaborase políticas públicas en materias de salud, educación, empleo y cultura desde la experiencia de las mujeres; la modificación de los contenidos educacionales; y el aseguramiento de un porcentaje de participación de las mujeres en los cargos de responsabilidad gubernamental. En el momento estas propuestas fueron vistas por los partidos de oposición como una acción excesivamente ambiciosa, sectorial, que conducía a dividir las fuerzas de la oposición (Frömann \& Valdés, 1993), por lo que no se prestó mucha atención al documento. Sin embargo, muchos de los elementos allí contenidos fueron empleados luego como base para la propuesta que captó más la atención de los partidos de la oposición, la elaborada por la Concertación de Mujeres por la Democracia.

\section{TRAMAS PARA UN NUEVO DESTINO: LA CONCERTACIÓN DE MUJERES POR LA DEMOCRACIA}

A fines de 1988 mujeres militantes de partidos y profesionales sin militancia partidaria, pero en su mayoría integrantes del movimiento de mujeres, se reúnen para crear una instancia política que hiciera patente la problemática de las mujeres a partir de la formulación de un programa para el futuro gobierno democrático. Esta instancia se denominó Concertación Nacional de Mujeres por la Democracia, autónoma de los partidos, pero vinculada a la Concertación de Partidos por la Democracia a través de su comisión técnica ${ }^{11}$.

Para elaborar el programa se creó una Comisión de Programa, que estaba articulada en 11 subcomisiones temáticas, a saber: Empleo, Educación, Salud, Familia, Comunicaciones, Arte y Cultura, Participación, Mujer Campesina e Indígena, Mujeres Pobladoras, Legislación, e Institucionalidad para la Mujer. A estas se sumaron un gran número de profesionales, así como también activistas y dirigentes del movimiento de mujeres y de partidos políticos, que dotó al espacio y al trabajo voces heterogéneas en términos políticos y técnicos. Según Teresa Valdés (1993), participante en las subcomisiones de Mujeres Pobladoras e Institucionalidad para la Mujer, el trabajo allí realizado permitió

\footnotetext{
${ }^{11}$ La Concertación de Partidos por la Democracia fue un conglomerado de partidos de centro y de la izquierda más moderada que deviene de la Concertación de Partidos por el NO creada en 1988 en la coyuntura del plebiscito de ese mismo año. Las y los primeros cuatro presidentes civiles tras la dictadura chilena pertenecieron a dicho conglomerado (1990-2010).
} 
la socialización de los conocimientos acumulados en las distintas áreas y la toma de conciencia, de unas- y otras de los problemas más relevantes en las áreas diferentes de la propia, la homogenización del diagnóstico de la situación de las mujeres chilenas y el encuentro entre especialistas y políticas. Este proceso tuvo también tuvo como consecuencia el establecimiento de lazos de confianza que facilitaría la posterior conformación del equipo de gobierno y la puesta en práctica de las propuestas elaboradas (p. 162).

En cuanto a la composición del espacio, varias de ellas venían del exilio, lo que supuso el encuentro con nuevas ideas y experiencias que volcaron en el trabajo en las comisiones de trabajo. Muchas de ellas fueron encargadas de subcomisión, como Verónica Báez-Salud-, Ximena Valdés-Mujeres Campesinas-, Keni Hirmas-Comunicaciones- y Carmen Gloria Aguayo-Mujeres Pobladoras-.

Al interior de la Concertación de Mujeres existió una propensión a destacar su participación, en tanto especialistas en la materia o en tanto apoyo técnico, más que por el valor político y experiencial que podía representar su participación en el movimiento social de mujeres, en caso de que así fuera. Ello evidenciaría un esfuerzo por obtener la validación de sus interlocutores en tanto lo allí expresado corresponde a estudios y a una profesionalización de la práctica que hacía más difícil impugnar ese trabajo. Pese a ello, según las entrevistas realizadas por Valdés y sistematizadas en el estudio citado a lo largo de estas páginas (1993), existe tanto un reconocimiento explícito por parte de sus integrantes hacia el movimiento social de mujeres como una vinculación intrínseca entre la Concertación de Mujeres, el programa que estas elaboran, y el mismo movimiento. De este modo, es posible constatar que en el programa que surge como resultado del trabajo de la Concertación, convergen distintas fuentes de información y experiencia: el saber y trayectoria individual; las investigaciones sobre la mujer ya elaboradas; y la acumulación de experiencias y saberes del mismo movimiento social de mujeres.

Una vez construido el programa, asumieron la tarea de difundir el trabajo y las propuestas allí contenidas a partir de la publicación de un libro en 1990, titulado "Tramas para un nuevo destino. Propuestas de la Concertación de Mujeres por la Democracia", editado por Sonia Montecino y Josefina Rossetti. El análisis de dicho documento que se realiza en las líneas que siguen es importante en tanto permite conocer las reflexiones y propuestas elaboradas por las mujeres hasta ese momento, además de las expectativas que estas tenían en relación a la acción del posible gobierno civil en relación a la condición de las mujeres chilenas. 


\section{Tramas para un nuevo destino}

El texto creado por este grupo de mujeres buscaba ofrecer una trama posible para leer la condición de las mujeres en Chile, dando a conocer el trabajo de las 11 subcomisiones, considerando el diagnóstico y las propuestas que a partir de él se construyen.

En términos generales, los diagnósticos elaborados en cada una de las subcomisiones comparten la visión de que las mujeres chilenas se encuentran en una condición de desigualdad y discriminación en relación a los hombres. Ello se acrecienta en ciertos grupos sociales y etarios específicos, como son las pobladoras, campesinas y adultas mayores. Esta condición de desigualdad la sitúan además en momentos en que se reconocen los cambios generados por el proceso de modernización y crisis nacional, en que las mujeres han conquistado nuevos espacios, así como también han sido llamadas a cumplir nuevos roles. Esto se expresa nítidamente en la subcomisión de Empleo, en que se comparte el análisis que, pese a que se ha abierto el mercado laboral para las mujeres, signo de modernidad, este lo hace bajo prismas discriminatorios en que las mujeres son aceptadas para cumplir ciertas labores-propias de su sexo- y bajo condiciones y salarios inferiores en relación a los hombres.

Si bien el principal interlocutor que tienen las propuestas es el futuro gobierno, en varios de los ejes se incorporan elementos dirigidos también a generar transformaciones a nivel de las relaciones interpersonales. De ahí que todos los ejes consideran dentro de sus diagnósticos y propuestas elementos referentes a la educación y el importante rol que esta cumple en la transformación de las relaciones entre los sexos. Además de la revisión y modificación de los textos escolares que tienden al fortalecimiento de estereotipos, también se hace referencia a la necesidad de incorporar ciertas temáticas a las mallas curriculares de las universidades, en miras de aumentar y mejorar el conocimiento existente sobre las mujeres. En una línea similar, en varias subcomisiones se sugiere el desarrollo de capacitaciones y cursos a distintos grupos y sectores sociales, orientados a generar conciencia en relación a la situación que viven las mujeres para así subvertirla no solo desde la acción institucional, sino que también desde la modificación de las prácticas cotidianas.

Por eso es que las propuestas tienden a hacer transversal los denominados temas de la mujer en términos institucionales, procurando que estos fuesen incorporados de lleno a la estructura del Estado a partir de la integración de distintos ministerios y poderes estatales en la planificación y materialización de las propuestas. 
Por otra parte, la mayoría de las subcomisiones incorporan dentro de sus propuestas la ratificación de la CEDAW, en tanto paraguas internacional que permitiría la inclusión e implementación de una serie de medidas orientadas a eliminar la violencia hacia las mujeres en distintos ámbitos. Sin duda, esta también se invoca como una estrategia de validación de las propuestas toda vez que se constituye como un acuerdo internacional que sistematiza e institucionaliza la problemática de la discriminación contra las mujeres.

Este ejercicio de validación de la propuesta de la Concertación de Mujeres también se da con las organizaciones del movimiento social de mujeres, proponiendo reformular la ley de Juntas de Vecinos, "de manera de dar cabida a la representación, no solo de los centros de madres, sino de las nuevas organizaciones femeninas surgidas durante los últimos años." (Montecino \& Rossetti, 1990, p. 178). Sin duda, lo anterior constituye un esfuerzo por incorporar en término valido a las organizaciones de mujeres en la nueva institucionalidad propuesta, así como también en la ejecución de los programas y acciones que allí se sugieren.

En este nuevo esquema existe una figura institucional muy relevante para la materialización de varias propuestas: la Oficina Nacional de la Mujer. Entre sus objetivos se encuentran el diseño y coordinación de políticas públicas específicas referidas a las mujeres, proponer modificaciones constitucionales y legales, y estimular la implementación de planes y programas a nivel regional y comunal, entre otros. A partir de aquellos se esbozan algunas funciones tales como diseñar y coordinar los planes, acciones y políticas nacionales respecto a las mujeres, garantizar y resguardar la presencia de mujeres especialistas en las instituciones públicas, realizar actividades de capacitación, y vincularse con organismos femeninos extranjeros. Visto así, la Oficina sería el espacio institucional centrado en atender la situación de las mujeres, permitiendo asegurar la instalación de estas propuestas y problemática a nivel estatal.

Pese a que el desarrollo del diagnóstico en cada una de las subcomisiones es bastante completo y profundo, lo cierto es que muchas de las propuestas no están del todo desarrolladas en cuanto a su implementación, proliferando el uso de verbos como "valorizar", "lograr", "promover", "propender" y "propiciar". Se podría especular que esto se debe al desconocimiento del funcionamiento interno de las instituciones estatales, o a la ausencia de instituciones capaces de hacerse cargo de las propuestas. Según lo señalado por una de las participantes del espacio:

Yo creo que estos proyectos adolecieron en general de un defecto, en la parte diagnóstico y estudios preliminares estuvieron muy bien, lo que nos ha faltado por falta de práctica es la capacidad operativa del proyecto. Nuestra falla no ha sido falta de conocimientos, 
ni de capacidad, sino falta de experiencia, pero estamos aprendiendo, estamos aprendiendo bien ligero en el sentido que todos estos proyectos tienen que tener una operatividad y un sentido muy preciso de dónde están las mayores urgencias. Hay conocimiento y hay práctica, pero también nos ha fallado ensamblar todo eso... (Citado en Valdés, 1993, p. 178)

Quizás por lo descrito en la cita anterior, o bien inspiradas por la forma adoptada por los partidos políticos a los que pertenecían algunas de las integrantes de la Concertación de Mujeres, en general el tono de las propuestas sigue la idea de en la medida de lo posible, intentando no incomodar lo planificado por los mismos partidos. Lo anterior se expresa incluso en el uso de recursos que algunas subcomisiones consideran para la ejecución de sus propuestas, los cuales son muy reducidos y en algunos casos inexistentes ${ }^{12}$, cuando en realidad al observar la naturaleza e impacto de las propuestas es evidente que estas requerían de un presupuesto estatal considerable.

Este tono cauteloso y tendiente a favorecer el consenso, no solo con los partidos políticos, sino que también al interior de la misma Concertación de Mujeres, es lo que explicaría que no haya ninguna mención en torno el aborto. Ello pese a que este tema estuvo presente entre las discusiones, panfletos y petitorios que las mujeres levantaron durante la década, e incluso en décadas anteriores. Si bien en el área de salud y familia se hace referencia a la necesidad de una educación sexual transversal, la difusión y entrega de métodos anticonceptivos, y la libertad de la mujer de decidir sobre la cantidad de hijos e hijas, el tema del aborto parece no existir.

La única mención al respecto se realiza por la subcomisión de Legislación. Esto se da en un pie de página al momento de abordar la situación de la mujer en el Derecho Penal chileno, en que se expresa que:

el tema del aborto no ha sido discutido en esta oportunidad. Debe sin embargo ser abordado. Se requiere un tratamiento adecuado y prevencional de los problemas que ocasiona el aborto y el embarazo precoz, en el caso de las adolescentes (Montecino \& Rossetti, 1990, p. 194).

Esta ausencia es bastante grave considerando que una de las últimas medidas del régimen dictatorial en esta materia fue la penalización del aborto terapéutico. Sin duda, este aspecto evidencia las diferencias ideológicas entre las mujeres participantes del espacio, las que se fueron profundizando hasta la instalación de una especie de agenda valórica en la postdictadura que encapsuló algunos elementos referentes a los derechos de las mujeres en una esfera intocable para el Estado y sus instituciones.

\footnotetext{
${ }^{12}$ Esto se expresa en las subcomisiones de Salud y Familia en que se señala que "las propuestas señaladas suponen una política que contemple el menor costo para el Estado".
} 
Desde el interior de la Concertación de Mujeres también se planteó la crítica que, en general, el Programa construido trabajaba con los problemas existentes para arreglarlos y no para subvertirlos (Valdés, 1993, p. 177). De ahí que el énfasis de las propuestas estuviese en mejorar la situación de las mujeres en diversos ámbitos, pero sin alterar demasiado la estructura de ciertas instituciones claves de la reproducción de los estereotipos de género que conducen a la violencia y la discriminación, tal como lo es la familia y el Estado.

\section{La recepción del programa}

El programa no fue aceptado del todo e, inmediatamente, por la Concertación de Partidos por la Democracia. Existió, primero, un trabajo de presentación y exposición de la propuesta y, luego, reuniones para idear la manera de incorporar algunos elementos allí contenidos en el programa de gobierno, para lo que algunas mujeres se incorporaron a distintas comisiones del área económico social de dicho conglomerado.

Si bien la Concertación de Mujeres por la Democracia logró el objetivo de elaborar una propuesta y presentarla a los partidos del conglomerado y a la sociedad, esta no logró mantenerse en el tiempo. Ello se debió, en parte, a la incomodidad que generaba su existencia como organismo cercano pero autónomo de la Concertación de Partidos.

De esta forma, la existencia de la Concertación de Mujeres fue corta y en conflicto tanto con el movimiento social de mujeres como con los partidos. La incapacidad de dicho espacio de reconocerse-y ser reconocidas y validadas-en alguno de esos dos lugares, dada la heterogeneidad de sus integrantes, evidenció las diversas visiones existentes sobre el proceso de cambio de régimen y, en específico, el rol que las mujeres debían o podían jugar en el mismo. Diversidad que responde, a mi juicio, a una diferencia mucho mayor, relativa a las concepciones presentes en las agrupaciones de mujeres y los mismos partidos sobre la democracia y las formas para construirla.

\section{COMENTARIOS FINALES: LA DEMOCRACIA EN DISPUTA}

Si se observan con detención los petitorios y las propuestas del movimiento de mujeres comentados a lo largo de estas páginas, todos están guiados por la premisa que plantea que, ante la ausencia o discriminación de un actor social de la política, no hay democracia posible de instalar. Es decir, que para 
poder hablar de un régimen democrático a lo menos se requiere la presencia y participación de las y los actores que forman parte de la sociedad.

Ahora bien, esta incorporación no podía realizarse pensando a las y los actores sociales como un grupo homogéneo, sino que considerando las especificidades que cada uno posee. De ahí que en los diagnósticos y propuestas que realizan las mujeres durante este periodo, pese a que reconocen una identidad genérica común, son enfáticas en que la vivencia-y las problemáticas-de las mujeres varían por razones etarias, socioeconómicas, étnicas, etc.

En ese sentido, más allá de la especificidad de las propuestas que cada uno de los documentos analizados plantea, estos logran expresar una visión y definición alternativa al concepto de democracia. Las propuestas de mujeres y feministas no apuntaban solo a cuestiones abordables a nivel estatal e institucional. También apelaban a transformaciones en las conductas diarias de las personas, en específico en lo relativo a la relación entre hombres y mujeres. Así, la democracia no sería una cuestión posible de resolver y decretar solo desde las instituciones. Además, debía expresarse en la cotidianidad y en las relaciones sociales que se establecen. Sin duda esto encuentra eco en la consigna democracia en el país y en la casa o en la premisa lo personal es político, toda vez que aquello que tradicionalmente era considerado como el espacio íntimo, en que hombres y mujeres habitaban a su antojo, ahora se transforma en un espacio de disputa política, indispensable para la democratización ${ }^{13}$. En otras palabras, la democracia no sería solo un tipo de gobierno sino que, ante todo, sería una forma de construir las relaciones entre las personas.

Tal vez por estas definiciones fue que el fin de la dictadura cívico-militar enfrentó a las mujeres a un debate que dividió aguas en relación al Estado y los partidos políticos. Y es que muchas mujeres veían en los partidos políticos y en el gobierno del Estado el rostro de viejas instituciones que por años las habían discriminado y marginado, de modo que no se constituían como figuras válidas para obtener las transformaciones por las que se habían organizado durante años. En ese sentido, en el caso de las mujeres no es posible hablar de una intención de retorno a la democracia, toda vez que esta no había existido antes para ellas, y muchas no estaban dispuestas a volver al lugar y rol que desempeñaban antes de la organización que desarrollaron durante la dictadura.

\footnotetext{
${ }^{13}$ Esto es lo que Julieta Kirkwood ha denominado como una visión no sexista de la política, en que se incorporan en término validos los experiencial privado y cotidiano (Kirkwood, 1983).
} 
Pese a las diferentes opiniones existentes sobre este tema, lo cierto es que el proceso de formulación de diagnósticos y de propuestas a la democracia, fue un proceso complejo y de muchos aprendizajes para el movimiento, en tanto permitió darle sustento y cierto grado de aplicabilidad a aquellas reflexiones y deseos que las mujeres tenían individualmente y que más tarde compartieron en algunos espacios colectivos.

El inicio de la post-dictadura enfrentó a las mujeres y feministas a nuevos desafíos, en que los gobiernos civiles fueron motivo, la mayoría de las veces, de un sentimiento de decepción que las impulsó a asumir diversas tácticas y estrategias para mantener vivas las demandas y propuestas de un movimiento que se negó a desaparecer.

\section{BIBLIOGRAFÍA}

Baldez, L. (2002). Why Women Protest: Women's Movements in Chile. Cambridge University Press. https://doi.org/10.1017/CBO9780511756283

Cuatro miradas al pliego de la mujer. (1986). Chile cooperativa, julio-agosto 1986. http://archivomuseodelamemoria.cl/uploads/1/8/185099/00000013500009000033.pdf

Frömann, A., \& Valdés, T. (1993). Democracy in the country and in the home: The Women's movement in Chile. FLACSO.

Gálvez, A. (2018). Historia del movimiento feminista en Chile en el siglo XX y su quiebre en la postdictadura. En J. Ponce, A. Pérez \& N. Acevedo (eds.), Transiciones: Perspectivas historiográficas sobre la postdictadura chilena 1988-2018 (pp. 285-310). América en Movimiento.

Garretón, M. A. (1989). La posibilidad democrática en Chile. FLACSO.

Garretón, M. A. (1990). Partidos políticos, transición y consolidación democrática. Proposiciones, (18), 72-84.

Gobierno de Chile (1974). 1974. Primer año de la reconstrucción nacional. Editorial Gabriela Mistral.

Godoy, O. (1999), La transición chilena a la democracia: Pactada. Estudios públicos, (74), 79-106.

Htun, M. 2010. Sexo y Estado. Aborto, divorcio y familia bajo dictaduras y democracia en América Latina. Ediciones Universidad Diego Portales.

Kirkwood, J. (1983). El feminismo como negación del autoritarismo. Documento de trabajo, (52). FLACSO.

Kirkwood, J. (1984). Los nudos de la sabiduría feminista. Material de discusión, (64). FLACSO. 
Montecino, S., \& Rossetti, J. (eds.). (1990). Tramas para un nuevo destino. Propuestas de la Concertación de Mujeres por la Democracia. Concertación de Mujeres por la Democracia.

Moulian, T. (1998). El Chile actual: Anatomía de un mito. LOM.

Ríos, M., Godoy, L., \& Guerrero, E. (2003). ¿Un nuevo silencio feminista? La transformación de un movimiento social en el Chile posdictadura. CEM; Editorial Cuarto Propio.

Palestro, S. (1991). Mujeres en movimiento 1973-1989. FLACSO.

Power, M. (2008) La mujer de derecha: El poder femenino y la lucha contra Salvador Allende 1964-1973. Dibam.

Tessada, V. (2013). Democracia en el país y en la casa. Reflexión y activismo feminista durante la dictadura de Pinochet (1973-1989). Cuadernos Kóre, (8), 96-117.

Valdés, T. (1987) Las mujeres y la dictadura militar en Chile. FLACSO.

Valdés, T. (1993). El movimiento social de mujeres y la producción de conocimientos sobre la condición de la mujer. FLACSO.

Valdivia, V. (2010). ¿Las mamitas de Chile? Las mujeres y el sexo bajo la dictadura Pinochetista. En J. Pinto (ed.), Mujeres. Historias chilenas del siglo XX (pp. 87-116). LOM.

Valenzuela, M. E. (1993). Las mujeres en la transición democrática. En P. Drake \& I. Jaksci (eds.), El dificil camino hacia la democracia en Chile (pp. 307-350). FLACSO. 